\title{
SILKSCARF: BRINGING BLACK HAIR INTO THE GIG ECONOMY
}

by

\author{
Lisa Afriyie
}

BA, English and Political Science, University of Toronto, 2013

\author{
A Major Research Project \\ Presented to Ryerson University \\ in partial fulfillment of the requirements for the Degree of \\ Master of Digital Media \\ in the program of Digital Media \\ Toronto, Ontario, Canada, 2019
}

(C) Lisa Afriyie, 2019 


\title{
AUTHOR'S DECLARATION
}

I hereby declare that I am the sole author of this MRP. This is a true copy of the MRP, including any required final revisions.

I authorize Ryerson University to lend this MRP to other institutions or individuals for the purpose of scholarly research.

I further authorize Ryerson University to reproduce this MRP by photocopying or by other means, in total or in part, at the request of other institutions or individuals for the purpose of scholarly research.

I understand that my MRP may be made electronically available to the public.

\author{
Lisa Afriyie
}




\title{
SILKSCARF: BRINGING BLACK HAIR INTO THE GIG ECONOMY
}

\author{
Lisa Afriyie \\ Master of Digital Media \\ Digital Media \\ Ryerson University, 2019
}

\begin{abstract}
This Major Research Project (MRP) explores the viability of and need for a black hair mobile application (app) that would provide a mapping of both hair salons and home-based mobile stylists using location-based data. Black women often have a hard time finding hairstylists due to the specific needs of black hair. This proposed product, tentatively titled SilkScarf, would connect customers to stylists who specialize in black hair, effectively solving the issue of access to black hair salons for black women in various black Caribbean and African communities. Because SilkScarf will serve both users and service providers, this MRP will detail the sense of community and economic agency that could be generated from such a product. This MRP will also explore how such a service would reconcile feelings of displacement, and unease that black women often deal with.
\end{abstract}




\section{ACKNOWLEDGEMENTS}

This Major Research Project would not have been possible without the excellent guidance

of my supervisor Dr. Cheryl Thompson. Thank you for your valuable feedback and ongoing support throughout the course of the project. I would also like to thank my mother, father and sister for their unrelenting support throughout all my endeavors as well my close friends. Thank you for always being there for me. 


\section{TABLE OF CONTENTS}

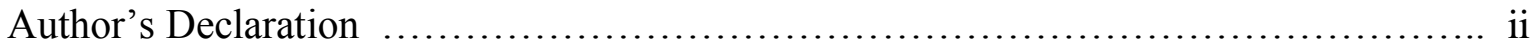

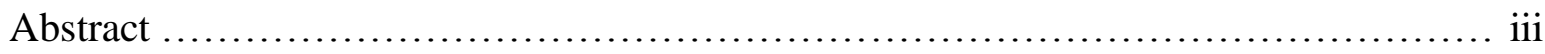

Acknowledgements ................................................................ iv

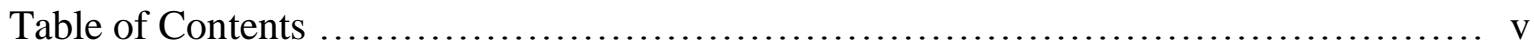

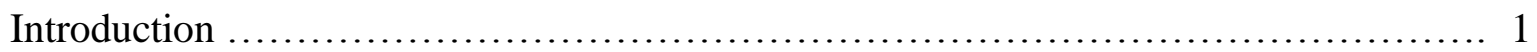

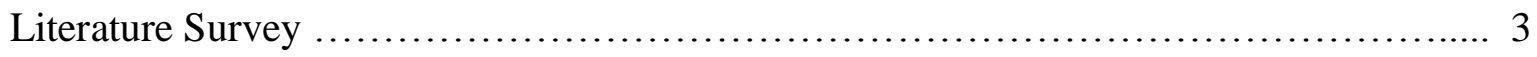

Historical Context ............................................................ 3

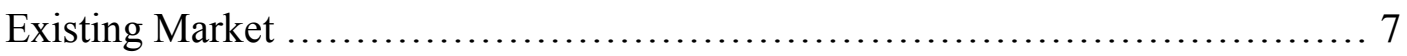

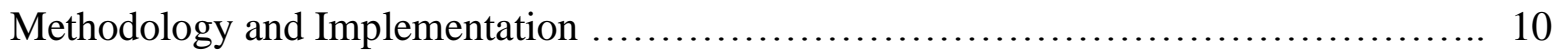

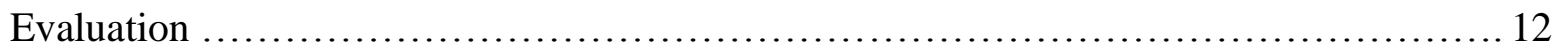

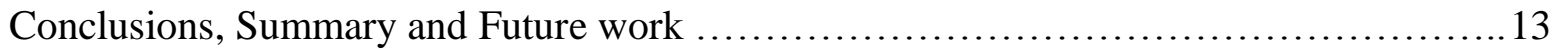

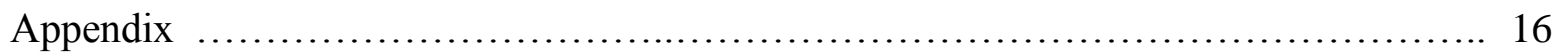

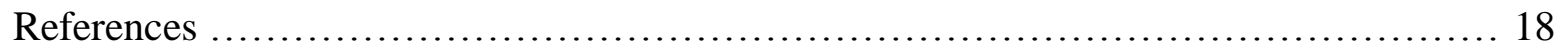




\section{IT'S NOT JUST HAIR: AN INTRODUCTION}

"To find a hairstylist who knows how to work with ethnic hair, you usually have to rely on word of mouth...Sometimes you just have to stop people on the street and ask where they go. I found my current hairstylist at Earth Salon in Yorkville by approaching a woman at Burger King" (Sylvestre-Williams, 2014). This statement made by journalist Renée Sylvestre-Williams in Toronto's Now Magazine frames a dilemma that black women globally know all too well. Finding an appropriate hairstylist is often a delicate balancing act, that conflates issues of location, price and expertise. The problem outlined here by Sylvestre-Williams is one concerning accessibility.

This Major Research Project (MRP), will explore the viability of and need for a black hair mobile application (app) that would provide a mapping of both hair salons and home-based mobile stylists using location-based data. This app (tentatively titled SilkScarf) would connect customers

to stylists who specialize in black hair, effectively solving the issue of access to black hair salons for black women in various black diaspora communities. Because SilkScarf intends to serve a twosided market of both user and service providers, this MRP will also detail the sense of community and economic agency that could be generated from such a product. This MRP will also explore how such a service would reconcile feelings of displacement, and unease, that black women often deal with.

When attempting to understand why there would be a need for this proposed product, it is essential to first explore the very particular needs of black hair. An assumed critique of such a venture would be "why specifically an app for black hair?". Some might think that there is no need for such a product as it is "just hair." In our hyper diversity-focused society, one would assume that a black woman could walk into any salon, request a style/service and have their hair taken care of in an appropriate manner. But this is far from the truth. Black hair is "thicker, curlier, and 
often frizzier as compared to Caucasian and Asian hair. And, from a grooming standpoint, it is also more sensitive to excessive manipulation, requiring a different set of styling techniques" (Thompson, 2008). As a result, styling such hair requires a particular skillset. Even with this documented fact, black women who dare to speak about the realities of styling their hair within a Eurocentric society are often dismissed with this same response: “it's just hair”.

"Well, here's the thing: It's not just hair. If it were just hair, then people wouldn't be fired or not considered for jobs because they have dreadlocks or because they have natural hair ... Hair is important."

- $\quad$ Zendaya Coleman, Actress (Hou, 2016)

This remark from actress Zendaya Coleman was in response to being asked about those who dismiss the delicate topic of black hair as being "just hair." Coleman is no stranger to hair discrimination herself. In 2015, while on the red carpet Guiliana Ranic, host for TV show Fashion Police, commented that her dreadlocked hair made her look like she "smells like patchouli oil. Or, weed" (Bryant, 2015). Such discriminatory comments are often par for the course when it comes to the matter of black hair. As evidenced by the scrutiny suffered by Coleman, it is clear. For black women, it is never "just hair." Author and researcher Dr. Cheryl Thompson explains in her book Beauty in a box that from childhood through to adulthood black women are faced with "constant reminders in the media and advertising positioning black women's bodies as Other and the visible markers of blackness-dark skin or "kinky" hair-as aberrant" (Thompson, 2019). For black women across the globe, this is their reality. While the hair care mobile app I propose may not completely resolve the feelings of otherness that black women often feel, it will address three concerns: access, choice and economic agency. 


\section{LITERATURE SURVEY}

\section{Historical Context}

Hair has always been a personal subject for most women, but these feelings are often magnified for black women in respect to how they manage their hair. Existing within the intersection of being both black and female, black women have historically had a harder time fitting into western beauty standards. For most of modern history, the western standard of beauty has been long, flowing and often blond hair. Black hair - typically dark, tightly coiled, growing upward instead of downwards - is on the opposite end of this spectrum. Additionally, it is not just black women living in western societies who have faced this issue. As a result of the long-standing legacy of the trans-Atlantic slave trade and colonialism, black women in communities that are typically described as homogeneous have also faced these same difficulties and societal pressures. Why is it that black women in various settings and circumstances have this same issue in common? One way of answering this question is looking at how black women have been treated at large in a global society ruled by whiteness.

Due to the specific needs of black hair, most black women often opt to go to black hairstylists to have their hair needs met. However, what happens when black haircare services are scarce? Historically, Black women have been shunned out of white beauty spaces. White stylists and salons have denied service to black women for years and although most women decide to go to hairstylists of their own race, there are some who choose to break the mold (Russell, 2008). In the United States denying service to black women who try to access white salons and stylists, is a breach of Title II of the Civil Rights Act of 1964: Injunctive Relief Against Discrimination in Places of Public Accommodation - a law set to promote equality and individual civil rights (Russell, 2008). Because of this law, a black woman should be able to walk into any salon and 
expect service, however, this is not often the case. In one prominent case, Debbie Deavers Sturvisant, a Black woman in Springville, Alabama, went to a Dillard's department store and was charged \$35 for a service that should have cost \$20 due to the texture of her hair (Russell, 2008). She went on to file a class-action lawsuit against the company (Russell, 2008). Black women who do choose to patron white salons are often faced with hairstylists who are not equipped to handle black hair or will charge a premium to do so.

For those who prefer to and have the opportunity to patron black hair salons, it can often serve as a comfortable safe space. Historically, black hair salons have been a source of not only refuge and comfort but also as a community gathering spot (Willet, 2000). Gossip, news, cultural, and political information are all common topics at a black hair salon, with frequent customers forming a family of sorts (Willet, 2000). Hair salon workers have often been "recognized as community leaders and beauty shops as important political institutions crucial to larger political struggles" (Willet, 2000). Black hair salons and workers have often had the capability of shifting larger conversations. For women who find themselves in new cities without a network, the community role that a hair salon fills is crucial.

In addition to being a community hub, the black hair salon also serves as a place where the economic agency of black women can be fully realized. Early research found that black women "spoke enthusiastically of beauty parlor work as a new opening for Negro women and a field which offers opportunities for better wages and more independence" (Willet 2000). The black hair salon and black hair culture in general was and is still is a place where black women, away from the confines of patriarchy, could often carve out a living for themselves. One of the most famous cases of a black woman doing so, is that of entrepreneur Madame C.J. Walker. Walker founded the Madame C.J. Walker Manufacturing Company that reportedly had more than 10,000 workers by 
the time of her death in 1919 (Thompson, 2019). The company famously developed a shampoopress-and-curl-method of straightening hair known as the "Walker System" (Thompson, 2019). As a result of the company's successes, Walker became the world's first woman millionaire (Thompson, 2019). This was no small feat for a black woman during this period and some would argue, it is still no small feat today.

Because the proposed SilkScarf app will be based and first launched in Canada, the context in which black hair and beauty practices exist in Canada must be considered. Black people in Canada make up $3.5 \%$ of the country population, equalling to close to 1.2 million people (Maheux \& Do, 2019). The vast majority of Canada's black population live in large urban areas (also known as Census Metropolitan Areas) such as Toronto, Montréal, Ottawa-Gatineau, Edmonton and Calgary (Maheux \& Do, 2019). A Census Metropolitan Area (CMA) is defined as one or more neighbouring municipalities situated around a population centre, with a total population of at least 100,000 , of which 50,000 or more live in the urban core (Maheux \& Do, 2019). Canada's black population has a history in the country that dates back to the 1600 s but only saw its numbers rise in recent years (Maheux \& Do, 2019). Much like in the United States, black Canadians found themselves excluded from the public sphere, and racist immigration policies prevented the population from growing (Thompson, 2019). It was not until after 1954 when immigration policies loosened, that the country saw an influx of black immigrants (Thompson 2019). Because of the close proximity of Canada and the United States it can easily be inferred that black hair culture in the former operates similarly to the latter. While this is true, one key difference is that the black population in the United States have historically been descendants of American slavery, with black immigrants arriving to the country in more recent years, while Canada's black population is primarily made up of immigrants who have arrived in the last 60 years (Maheux \& Do, 2019). 
What this means is that Canada's black hair history is much shorter and is not as embedded into the public consciousness as it is in the United States. However, much like in the United States, black hair and haircare serve as a way in which black women can become successful entrepreneurs. One prominent case is that of Viola Desmond, an African Nova Scotian woman living in what was at the time a segregated 1930s Halifax (Thompson, 2019). Halifax is home to Canada's oldest black population with ties dating back to the country's earliest days (Maheux \& Do, 2019). Desmond, now known for her advocacy for integration, was a Canadian entrepreneur inspired by the famed Madam C.J. Walker (Thompson, 2019). She attended beauty school in the United States and afterwards returned back to Canada to open a beauty shop in Nova Scotia (Thompson, 2019). She ultimately saw success as the salon drew customers from across the province, and eventually branched out into creating a product line (Thompson, 2019). Even in present day black Canadian women have continued to carve out a living for themselves via haircare.

However, the advent of social media has served as a turning point in this complicated hair history. YouTube, Instagram along with countless black hair blogs and forums have exploded in popularity over the last decade, giving black women an online safe space in which they can learn to style/groom their hair, and share tips with one another. Women can now refer to these hair blogs, Instagram accounts and YouTube channels catered to black hair in order to not only learn as mentioned, but to also find a community. There are currently over 133 million black hair blogs and YouTube channels and the phenomenon shows no signs of slowing down (Gill, T. M. 2015). Black hair has now entered the digital age.

As stated earlier, black hair salons often serve as a community gathering spot, and previously, it was the beauticians who owed these shops who worked to transform them into spaces that impacted the lives of the women who frequented them in a social, political and economic manner 
(Gill, T. M. 2015). Currently, although these shops are still frequented those in communities in which they are located, women looking to learn how to style and groom their hair are more likely to look for resources online (Gill, T. M. 2015). Social media now closely mirrors the function of a traditional physical beauty salon and this shift has also coincided with the rise of black women "going natural" also known as the natural hair movement (Ardito, Buono, Caivano, Costabile, \& Lanzilotti, 2014). The term natural in this context means the hair, (typically a curly or tightly coiled texture) of African-descended people worn in its natural state without chemical straighteners/relaxers (also known more colloquially as relaxers). As a result of the current popularity of natural hair, relaxer sales have fallen to $22.7 \%$ between 2016 and 2018 according to market intelligence agency's Mintel's annual U.S. Black Haircare Market Report, with strong indications of a continued decline (2018). Relaxer upkeep typically requires frequent visits to the hair salons for touch-ups and styling, however the decline in relaxer usage has resulted in a move away from the frequent patronage of beauty salons and an increase in more do-it-yourself (DIY) approaches to haircare. Social media is a documented growth channel for the black haircare market with $68 \%$ of Black women aged 18-34 showing interest in using social media to search for howto videos (Mintel, 2018). The research overwhelming indicates that black women are increasingly seeking hair information online, rather than attending black hair salons.

\section{Existing Market}

When looking to build a mobile app such as SilkScarf, it is important to consider the marketplace in which it will exist. There are currently several mobile apps and websites that use ratings, reviews and upvote features with one of the most notable being Yelp. Yelp is an online platform founded in 2004 with the intention of helping individuals find "great local businesses like dentists, hair stylists and mechanics" (Yelp, 2019). Traditionally those looking for 
recommendations for businesses or service resort to word of mouth (WOM) suggestions. WOM has frequently been proven to "exert great influence on consumer decision-making" (Lim \& Van Der Heide, 2015). WOM is typically explained as information transferred through "interpersonal networks in face-to-face settings" (Lim \& Van Der Heide, 2015). Customers typically find information received through WOM more reliable and credible than marketing based information (Lim \& Van Der Heide, 2015), meaning that customers are more likely to the trust the reviews and feedback provided to them by their friends and peers. WOM that occurs via the internet can be referred to as electronic word of mouth (eWOM) (Lim \& Van Der Heide, 2015). One of the benefits of eWOM is that unlike traditional face-to-face WOM, customers have access to a much wider network and information can be transmitted in a much shorter timeframe (Lim \& Van Der Heide, 2015). However the ability to leave reviews so easily presents a dilemma as well. It is much harder for reviews to be verified, leading to credibility issues for the customer seeking reviews (Lim \& Van Der Heide, 2015). When discussing online reviews credibility refers to a "person's perception of the truth of a piece of information" (Eisend, 2006). One way of solving this issue is a system in which both the customer and service provider are rated and reviewed. Ratings across transactions leads to more civil interactions and honest reviews because both the customer's and service provider's reputations are at stake (Anani, 2018). This is a common feature seen in apps that utilize the "gig" economy. Currently, one major shift that has taken place is the influx of mobile apps that allow individuals to participate in the workforce on a "gig" basis (Anani, 2018).

The gig economy is defined by the prevalence of short-term contracts or freelance work across a variety of employers as opposed to permanent jobs (Torpey \& Hogan, 2016). The gig economy also includes the sharing economy which is typically characterized as "activity facilitated by digital 
platforms where people rent their skills and/or make their resources available for money" ("Daily — The sharing economy in Canada," 2017). Current leaders and drivers in this space are companies like AirBnB, Uber, and UpWork (Anani, 2018). These companies are the forefront of the current labour transformation in which more people are working outside of traditional full-time jobs (Anani, 2018). This shift has also accelerated "the digitization of social processes" ranging from cooking a meal, traveling, to consuming media, interacting with friends, and dating (Jung, Bapna, Ramaprasad, \& Umyarov 2019).

In terms of companies in the beauty space, SilkScarf would be directly competing with apps such as StyleSeat and Swivel. StyleSeat is described as an online destination for beauty \& wellness professionals and clients (StyleSeat, 2019). Via this app users can browse the work of beauty professionals, book appointments and leave reviews (StyleSeat, 2019). The Swivel app offers similar services, however the key difference between the two is that Swivel is targeted towards black women. Although, StyleSeat features hairstylists that specialize in black hair, it is still very much an app for the general public. StyleSeat is available in Canada, while Swivel is only currently available in select cities in the United States. Additionally, while the Swivel app like SilkScarf is targeted towards black women and offers users a chance to input their hair type (Swivel, 2019), SilkScarf offers further personalization by allowing users to input moisture levels, hair structure type, and recommending stylists to users based on this information. Personalization in this context refers the act of a corporation identifying and treating its consumers as individuals via personal messaging, targeted advertisements and other personal transactions (Kang \& Namkung, 2019) (Imhoff et al., 2001). Personalization is proven to be effective as it provides more opportunities for organizations to connect and develop relationships with customers (Nyheim, Xu, Zhang, \& Mattila, 2015). It is also beneficial as it minimizes the time customers spend looking for a product 
or service (Srinivasan, Anderson, \& Ponnavolu, 2002). By personalizing the user experience, customers are more easily able to compare and contrast services (Srinivasan et al., 2002). SilkScarf providing personalization in this manner allows for the best possible user experience.

\section{BRINGING BLACK HAIR INTO THE TECH AGE: METHODOLOGY AND IMPLEMENTATION}

Overview

The artifact created for the purposes of this MRP is a native mobile app prototype. A native mobile app is developed specifically for one platform in order to take advantage of a device's hardware capabilities and is installed through an application such as Apple's app store or Google play (Seymour, Hussain, \& Reynolds, 2014). A prototype acts as a "medium of communication between users and designers" which in turn helps the designer gather information about what the user wants and expects from the product (Dhillon, G.S. \& Smith-Jackson, Tonya \& Dhillon, B.K., 2012). Prototypes have varying degrees of fidelity but typically fall into either the low-fidelity or high-fidelity categories. Fidelity is the degree of closeness to the intended product (Dhillon et al., 2012). There are five dimensions that determine whether or not a prototype is low-fidelity or highfidelity. These dimensions, created by McCurdy et al (2006), are: (1) visual refinement, (2) breadth of functionality, (3) depth of functionality, (4) richness of interactivity and (5) richness of data model.

As a black woman, this app is targeted towards women of my demographic (20-something, entry-level to mid-level workers, with frequent social media usage). When gathering insight on potential users, I first started with my own lived experience. The idea for this project came from the frustration I have encountered when dealing with my own hair and witnessing the frustrations 
of others close to me. I thought of the pain points I had (i.e. cost, money, expertise) and I made an educated guess that the best way to resolve these issues would be through the implementation of a mobile app that utilizes location data. To validate these initial assumptions, I engaged in three forms of research: analyzing news pieces, analyzing scholarly articles and analyzing the habits of my assumed target market via secondary research.

When starting the process of creating a prototype for this app, I first started with a literature review. Creating products that cater to a particular race or gender often raises questions of why, so I used the literature review to address these questions and justify my decision to create this app. This review consisted of research that would explain the context and need for a black haircare app as well as a brief overview of the marketplace this product would be entering into. I then went on to create two user personas - one for the customer (Appendix A), and one for the hairstylist (Appendix B). These user personas detailed the motivation that these two users would have in becoming users of this app. User persona 1 is that of Curly Chloe. Curly Chloe is a university graduate who just moved to a new city and is looking for a new stylist. Her dilemma is that she has a lack of network, lack of time and is looking to save money. User persona 2 is that of Talented Tiana. She is a part-time student who works a part-time job and styles hair on the side for extra money. Her dilemma is that she has a lack of clients and is in need of extra income.

After creating these user personas, I created both low-fidelity and high-fidelity prototypes. I first created a wireframe, which is a low-fidelity mock-up typically drawn on paper. This wireframe allowed me to gain a sense of what this product should look like. I then used this information to create a high-fidelity digital prototype. 


\section{Materials used}

The high-fidelity digital prototype was created using Adobe XD, an app belonging to the Adobe Creative Suite that allows users to design, prototype, and share UI/UX (User Interface and User Experience) prototypes (Adobe, 2019). Images incorporated into the prototype are images from the stock image site Freepik.com, that I further customized using Adobe Illustrator and Adobe Photoshop.

\section{EVALUATION}

SilkScarf is a mobile app that helps users find hairstylists who specialize in black hair using location data. The main features of this app are the following:

1. Hair stylist recommendations based on hair type and hair

2. The ability to search for a stylist and chat with stylists

3. The ability to book appointments

4. The ability to leave/receive reviews and ratings

5. The ability to browse through stylist work

As mentioned earlier, the final artifact created for this project was a high-fidelity digital prototype. This prototype had two previous iterations before the creation of the final version. The first version (Appendix C.) consisted of screens that included features 2-5 but was lacking a feature where users could input their hair needs and be recommended a hairstylist. Additionally, the gradient overlay seen at the top of the screens did not feel modern enough and the overall colour scheme lacked warmth - important when addressing an intimate issue like hair. This version was missing a bottom navigation bar - vital for easy usability. 
The second version of this prototype (Appendix D) included updated illustrations and featured an aesthetic that felt more relaxed and inviting. This version included an option to tailor and personalize the experience by allowing the user to input their hair type. A navigation bar including a chat function, home button and settings was added for increased usability.

The final version of this prototype (Appendix E) featured a brighter colour scheme with matching illustrations making for an overall more cohesive feel. The bottom navigation bar was updated to include chat, search, notification, and personal profile features, while the settings function was moved to the hamburger menu seen in the top right corner. This final version had increased visual refinement, breadth of functionality, depth of functionality, richness of interactivity. Several screens were added to improve interactivity and allow this final version to mimic the experience of a developed mobile app as closely as possible. The user interface (UI) in this final version was flattened to match the current trend of flat minimal UI popularized by Apple (Verve, 2015).

\section{CONCLUSIONS, SUMMARY AND FUTURE WORK}

In the twenty-first century, the gig economy is becoming a major driver in the global job market. A service that bridges this sector with black hair care could serve as a way to boost black female economic agency in modern terms. Black female entrepreneurs now more than ever have an opportunity to disrupt the black hair care industry. SilkScarf, a location-based hair app that serves a two-sided market could be the solution that provides beauty access and community for black women, especially in smaller communities as well as economic agency for black women worldwide. Women seeking the welcoming, community aspect of the traditional beauty parlour would be able to find it via this app. 


\section{Future Work: Bringing SilkScarf to Market}

The end goal of this project is to create an MVP (minimum viable product), empower black entrepreneurs, and empower black consumers by increasing access to salons and community. To first create an MVP, I will need to code and develop a mobile app built for both the iOS and Android platforms. To bring this product to market I will be using the lean start-up methodology. The lean start-up methodology has three key principles:

1. Entrepreneurs must accept that all they have in the beginning is a series of untested hypotheses.

2. Entrepreneurs must use an approach "get out of the building". This approach calls for potential start-ups to go out ask potential users, purchasers and partners for feedback on their business model, effectively testing their hypotheses. This is to ensure nimbleness and speed.

3. Start-ups must practice agile development. This product development method eliminates long product development cycles in which companies test products with assumed knowledge of customer needs. With this method, the start-up creates the minimum viable products they test. Failing fast and learning fast is the idea here.

- $\quad$ (Blank, 2013)

This methodology also includes a tool called the "Lean Start-up Canvas" - a business model canvas that allows one to look at all nine building blocks of their company on one page. The first block on this page is identifying the problem. To achieve this SilkScarf will begin its rollout with its first target market: Canada. However, with such a large undertaking some initial statistics and research will have to be collected first in order to truly identify and cement the 
problem. As evidenced by the literature examined earlier, much of the narratives and research regarding black hair originates from the United States, with African American beauty entrepreneurs having asserted themselves "as the world's premier authorities on black beauty to people of color around the globe" (Ardito, et al., 2014). Because Canada has minimal research regarding data on Black Canadians and black hair, I will have to conduct some initial research myself or possibly in collaboration with other academic researchers. Increasing the amount of research originating from Canada will allow black Canadians a seat at the table in the global conversation about black hair.

Although a longer term goal for this project would be for it to compete in the global market, this project plans to first start small before scaling. This app would first be introduced in Canada's Census Metropolitan Areas (CMAs) as $94.3 \%$ of black people in Canada live in these areas (Maheux \& Do, 2019) before expanding to the rest of the country and internationally. During its rollout in Canada, this app would be expanded to include black men and barbers, as this is currently an underserved market. Additionally, among the Black population, 12\% have reported being both "White" and "Black" in the 2016 Canadian Census (Maheux \& Do, 2019), indicating that this is a fast growing category. Mixed-race individuals will also be accommodated in the future rollout of this app making for an inclusive experience for all black Canadians. 
APPENDIX

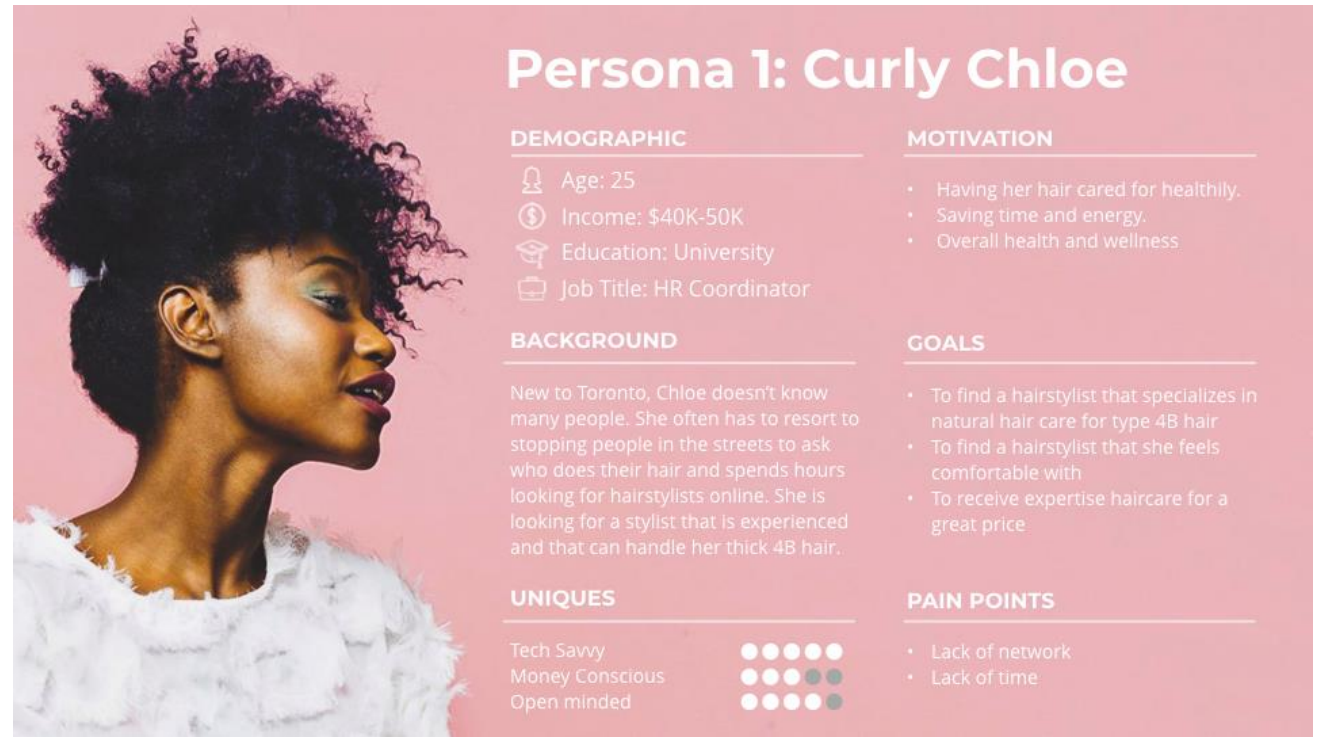

Appendix A. Persona 1: Curly Chloe

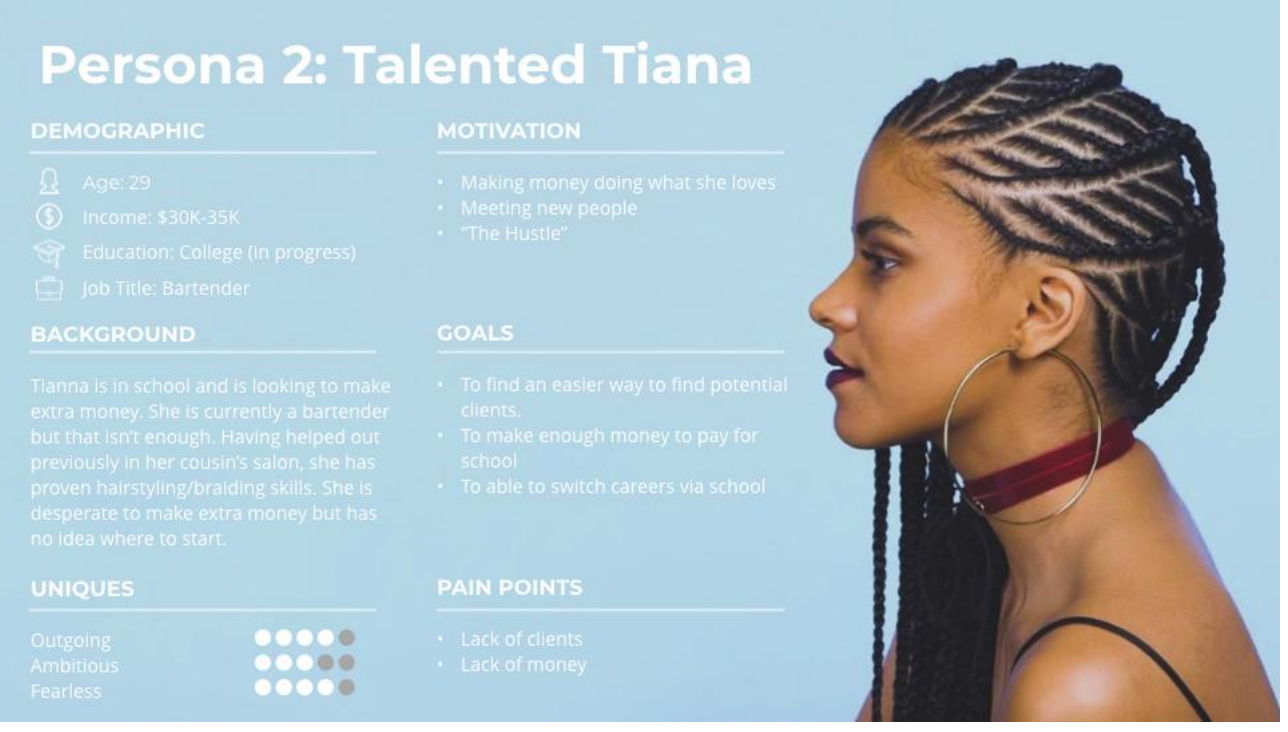

Appendix B. Persona 2: Talented Tiana 

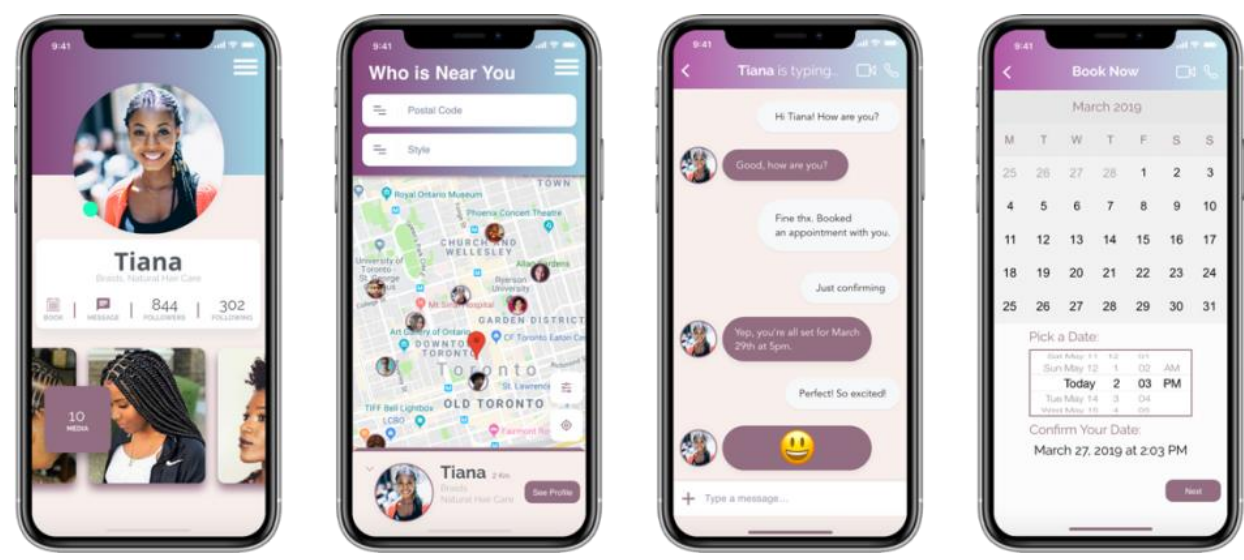

Appendix C. Prototype version 1
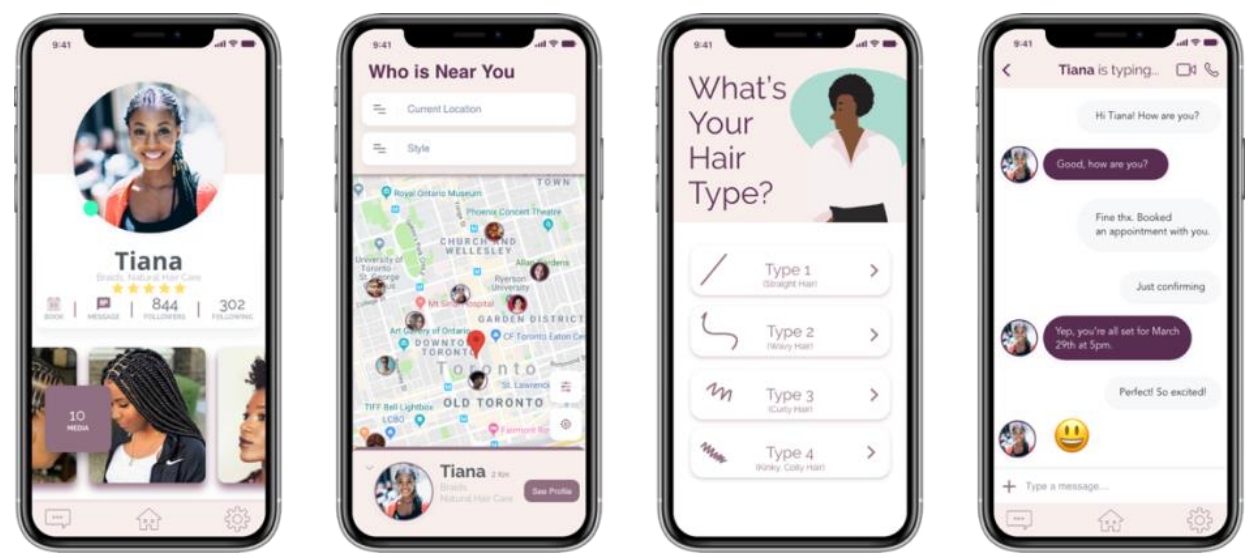

Appendix D. Prototype version 2
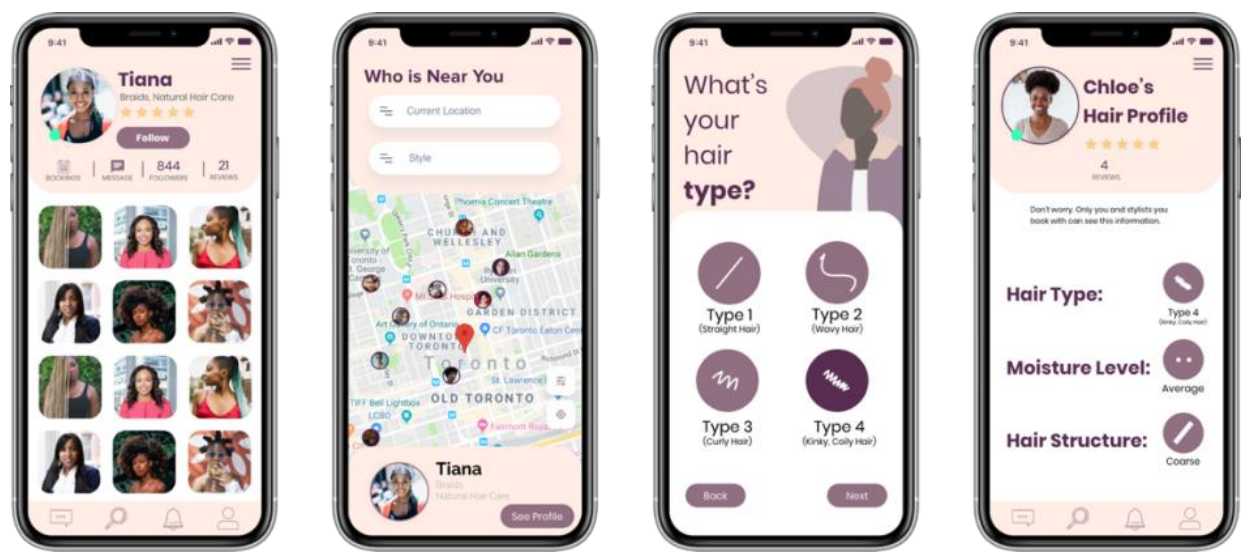

Appendix E. Prototype version 3 - Final version 


\section{REFERENCES}

Adobe. (2019). Create and share designs, layouts, and prototypes quickly | Adobe XD. Retrieved From https://www.adobe.com/ca/products/xd/details.html?promoid=599F8RK9\&mv=other

Anani, N. (2018). Paving the Way for the Future of Work. Canadian Public Policy, 1-10. doi:10.3138/cpp.2018-012

Ardito, C., Buono, P., Caivano, D., Costabile, M. F., \& Lanzilotti, R. (2014). Investigating and promoting UX practice in industry: An experimental study. International Journal of Human-Computer Studies, 72(6), 542-551. doi:10.1016/j.ijhcs.2013.10.004

Blank, S. (2013, May 1). Why the Lean Start-Up Changes Everything. Retrieved from Harvard Business Review website: https://hbr.org/2013/05/why-the-lean-start-up-changeseverything

Bryant, T. (2015, February). Zendaya Responds To Giuliana's Comments About Her Dreadlocks. Retrieved from https:/www.refinery29.com/en-us/2015/02/82786/zendaya-giulianarancic-dreadlock-comment

Dhillon, G.S. \& Smith-Jackson, Tonya \& Dhillon, B.K.. (2012). Effect of user's mood on technology acceptance of high-fidelity and low-fidelity prototypes. 62nd IIE Annual Conference and Expo 2012. 3477-3486.

Eisend, M. (2006). Source Credibility in Marketing Communication. Marketing ZFP, 28(JRM 1), 43-62. doi:10.15358/0344-1369-2006-jrm-1-43

Gill, T. M. (2015). \#Teamnatural: Black Hair and the Politics of Community in Digital Media. Nka: Journal of Contemporary African Art 37, 70-79. Duke University Press. Retrieved July 4, 2019, from Project MUSE database.

Hou, K. (2016, March 16). Zendaya on How to Love Yourself and Your Hair. Retrieved from https://www.thecut.com/2016/03/zendaya-hair-interview.html

Imhoff, C., Loftis, L., \& Geiger, J. G. (2001). Building the Customer-Centric Enterprise: Data Warehousing Techniques for Supporting Customer Relationship Management. Hoboken, NJ: Wiley.

Jaima, F. R. (2017). When things get hairy: Afros, cornrows, and the desegregation of US 
military hair salons in west germany. African and Black Diaspora: An International Journal, 10(3), 269-280. doi:10.1080/17528631.2017.1363477

Jung, J., Bapna, R., Ramaprasad, J., \& Umyarov, A. (2019). Love Unshackled: Identifying the Effect of Mobile App Adoption in Online Dating. MIS Quarterly, 43(1), 47-72. doi:10.25300/misq/2019/14289

Kang, J., \& Namkung, Y. (2019). The role of personalization on continuance intention in food service mobile apps. International Journal of Contemporary Hospitality Management, 31(2), 734-752. doi:10.1108/ijchm-12-2017-0783

Lim, Y., \& Van Der Heide, B. (2015). Evaluating the wisdom of strangers: The perceived credibility of online consumer reviews on yelp. Journal of Computer-Mediated Communication, 20(1), 67-82. doi:10.1111/jcc4.12093

Madame Noire. (2010, September 27). Why Do Koreans Own The Black Beauty Supply Business? Retrieved from https://madamenoire.com/104753/why-do-koreans-own-theblack-beauty-supply-business/

Russell, Constance Dionne, Styling Civil Rights: The Effect of Section 1981 and the Public Accommodations Act on Black Women's Access to White Stylists \& Salons (Spring 2008). Harvard Black Letter Law Journal, Vol. 24, No. 189, 2008. Available at SSRN: https://ssrn.com/abstract=1268133

Maheux, H., \& Do, D. (2019, February 27). Diversity of the Black population in Canada: An overview. Retrieved from https://www150.statcan.gc.ca/n1/pub/89-657-x/89-657x2019002-eng.htm

McCurdy, M., Connors, C., Pyrzak, G., Kanefsky, B., \& Vera, A. (2006). Breaking the fidelity barrier. Proceedings of the SIGCHI conference on Human Factors in computing systems - CHI '06. doi:10.1145/1124772.1124959

Mintel. (2018, October 9). Black women say their hair makes them feel beautiful. Retrieved from https://www.mintel.com/press-centre/beauty-and-personal-care/naturallyconfident-more-than-half-of-black-women-say-their-hair-makes-them-feel-beautiful

Nyheim, P., Xu, S., Zhang, L., \& Mattila, A. S. (2015). Predictors of avoidance towards personalization of restaurant smartphone advertising. Journal of Hospitality and Tourism Technology, 6(2), 145-159. doi:10.1108/jhtt-07-2014-0026

Seymour, T., Hussain, J. Z., \& Reynolds, S. (2014). How To Create An App. International 
Journal of Management \& Information Systems (IJMIS), 18(2), 123.

doi:10.19030/ijmis.v18i2.8494

Srinivasan, S. S., Anderson, R., \& Ponnavolu, K. (2002). Customer loyalty in e-commerce: an exploration of its antecedents and consequences. Journal of Retailing, 78(1), 41-50. doi:10.1016/s0022-4359(01)00065-3

StyleSeat. (2019). What is StyleSeat? Retrieved from https://styleseathelp.zendesk.com/hc/enus/articles/115012815868-What-is-StyleSeat-

Swivel. (2019). Retrieved from https://www.swivelbeauty.com/

Sylvestre-Williams, R. (2014, October 30). How to find a hairstylist who can work with ethnic hair. Retrieved from https://nowtoronto.com/lifestyle/how-to-find-a-hairstylist-who-canwork-with-ethnic-hair/

The Daily — The sharing economy in Canada. (2017, February 28). Retrieved from https://www150.statcan.gc.ca/n1/daily-quotidien/170228/dq170228b-eng.htm

Thompson, C. (2019). Beauty in a Box: Detangling the Roots of Canada's Black Beauty Culture. Waterloo: Wilfrid Laurier Univ. Press.

Thompson, C. (2008). black women and identity: What's hair got to do with it? Michigan Feminist Studies, 22(1)

Torpey, E., \& Hogan, A. (2016, May 10). Working in a gig economy : Career Outlook: U.S. Bureau of Labor Statistics. Retrieved from https://www.bls.gov/careeroutlook/2016/article/what-is-the-gig-economy.htm

Verve. (2015, July 6). The History of Flat Design [INFOGRAPHIC]. Retrieved from https://www.verve-design.co.uk/latest-news/history-of-flat-design-infographic/

Willett, J. A. (2000). Permanent waves: The making of the American beauty shop. New York: New York University Press.

Wingfield, A. H. (2009). Doing business with beauty: Black women, hair salons, and the racial enclave economy. Lanham, MD: Rowman \& Littlefield Publishers.

Yelp. (2019). About Us. Retrieved from https://www.yelp.ca/about 